\title{
The educational challenge of Paediatric Virology: An interview with Professor of Neonatology Anne Greenough
}

\author{
IOANNIS N. MAMMAS and DEMETRIOS A. SPANDIDOS \\ Department of Clinical Virology, School of Medicine, University of Crete, Heraklion 71003, Greece
}

Received July 18, 2017; Accepted August 22, 2017

DOI: $10.3892 /$ etm.2017.5007

\begin{abstract}
According to Professor Anne Greenough, Professor of Neonatology and Clinical Respiratory Physiology at the King's College London (London, UK), Paediatric Virology is indeed a rapidly increasing educational challenge. Professor Greenough, who in 1992 wrote her book on congenital, perinatal and neonatal infections, believes that during the past 3 decades, paediatric health professionals are becoming increasingly involved in specialised care and follow-up of paediatric patients with viral diseases, who require advanced medical care and innovative technological services. Moreover, she highlights the expected role of new vaccines and antiviral agents that are currently under investigation, as well as the impact of emerging viral diseases that require novel prevention strategies and therapeutic protocols. However, she notes that the number of Paediatric Virologists in any one country is likely to be small; hence, a separate paediatric subspecialty needs to be considered carefully. In the context of the 3rd Workshop on Paediatric Virology, which will be held in Athens, Greece, on October 7th, 2017, Professor Greenough will give her plenary lecture on the impact of viral infections on the long term outcomes of prematurely born infants.
\end{abstract}

\section{Contents}

1. Introduction

2. Questions and Answers

\section{Introduction}

Born in Newcastle, UK, Professor Anne Greenough (Fig. 1), one of the most famous and talented British Neonatologists

Correspondence to: Professor Demetrios A. Spandidos, Department of Clinical Virology, School of Medicine, University of Crete, Heraklion 71003, Greece

E-mail: spandidos@spandidos.gr

Key words: Paediatric Virology, Medical Education, neonatology, Anne Greenough worldwide, was educated in the UK at the University of Cambridge and the University College in London (1). She is a Professor of Neonatology and Clinical Respiratory Physiology at the King's College London (KCL) and Director of Education and Training at King's Heath Partners Academic Health Science Centre. She was Chair of the National Institute for Health Research (NIHR) Paediatrics Specialty Group and she is now Vice President of Science and Research at the Royal College of Paediatrics and Child Health ( $\mathrm{RCPCH})$. She is a member of the KCL Research Division of Asthma, Allergy and Lung Biology and the Medical Research Council-Asthma UK Centre in Allergic Mechanisms of Asthma. Her research interests include congenital, perinatal and neonatal infections, antenatal lung growth, optimisation of respiratory support, sudden infant death syndrome and the management of chronic lung disease. In 1992, she wrote her book on congenital, perinatal and neonatal infections (2), while in 1995, she co-authored a book on neonatal respiratory disorders (3). Recently, on May 25th, 2017, she was awarded the James Spence Medal, which is the highest honour awarded by the $\mathrm{RCPCH}$ for the most outstanding contribution to paediatric knowledge. Professor Greenough is indeed a great pioneer of modern Neonatology in the entire History of Medicine, who can be undoubtedly known as our 'Queen of Neonatology'.

To date, Professor Greenough has actively supported the Paediatric Virology Study Group (PVSG) and has offered valuable advice to the Workshops on Paediatric Virology (4-7). In 2015, she co-chaired the 1st Workshop on Paediatric Virology in collaboration with Professor Maria Theodoridou, Emeritus Professor of Paediatrics at the University of Athens School of Medicine in Greece and Professor Anna Kramvis, Research Professor of Molecular Virology at the University of the Witwatersrand in Johannesburg, South Africa, and she gave one of the three plenary lectures of that event $(4,5)$. She also actively participated in the PVSG on the working proposal of Paediatric Virology as a paediatric subspecialty (6), while in 2016 she evaluated the 2nd Workshop on Paediatric Virology (7). To date, Professor Greenough has received the '2015 Paediatric Virology Award in Neonatology' for her contribution on congenital, perinatal and neonatal infections (1), as well as the '2017 George N. Papanicolaou Humanitarian Award' for her outstanding academic, clinical, research and publishing contribution on the wealth, health and future of humanity. In the context of the 3rd Workshop on Paediatric Virology, which will be held in Athens on 
October 7th, 2017 (8), she will give her plenary lecture on the impact of viral infections on the long term outcomes of prematurely born infants.

\section{Questions and Answers}

Question: Professor Anne Greenough, first of all, thank you for your co-chairship and plenary lecture at the 1st Workshop on Paediatric Virology, which was held in 2015, as well as your acceptance to co-chair the 3rd Workshop on Paediatric Virology. This year, your plenary lecture will focus on the impact of viral infections on the long-term outcomes of prematurely born infants. How would you evaluate the programme of this workshop? Would you consider it useful for paediatric trainees?

Answer: Yes I do. The proposed agenda gives a comprehensive view of the impact of viral infections on children and hence is extremely useful for paediatric trainees. I am sure that your conference will be a major success highlighting important recent contributions to the impact of viral disease on neonatal and paediatric outcomes. I do hope the workshop will be a regular event.

Question: How could we improve our meeting?

Answer: It would be perhaps helpful at the next meeting to have shorter presentations so the chairpersons could have time to stimulate more audience participation. It may be beneficial to encourage local faculties presenting research findings. I would be pleased to help in any future conference.

Question: Would you consider that the creation of an educational e-platform on Paediatric Virology could help paediatric trainees and health professionals on infectious diseases?

Answer: Paediatric health professionals and trainees have an increasingly clinical workload with less time to undertake Continuing Professional Development (CPD) within their job plans. Creation of an educational e-platform on Paediatric Virology will be of great help as this could be accessed in their own time to update them.

Question: During the past 2 decades, there have been several exciting developments in the field of Clinical and Molecular Virology, which have expanded our knowledge base of viral infections occurring in neonates and children. What is the importance of these advances on neonatal and paediatric infections in the current clinical practice?

Answer: New vaccines and antiviral agents are currently under investigation, while emerging viral diseases require novel prevention strategies and therapeutic protocols. In addition, during the past 3 decades, paediatric health professionals are becoming increasingly involved in specialised care and follow-up of Oncology, Neonatal Intensive Care Unit (NICU) and Paediatric Intensive Care Unit (PICU) patients, transplant recipients and children infected with human immunodeficiency virus (HIV), who require advanced medical care and innovative technological services. Moreover, recently newfound social issues have arisen, including the anti-vaccination wave, the financial crisis and the unprecedented human migrations occurring globally and in the Mediterranean countries in particular.

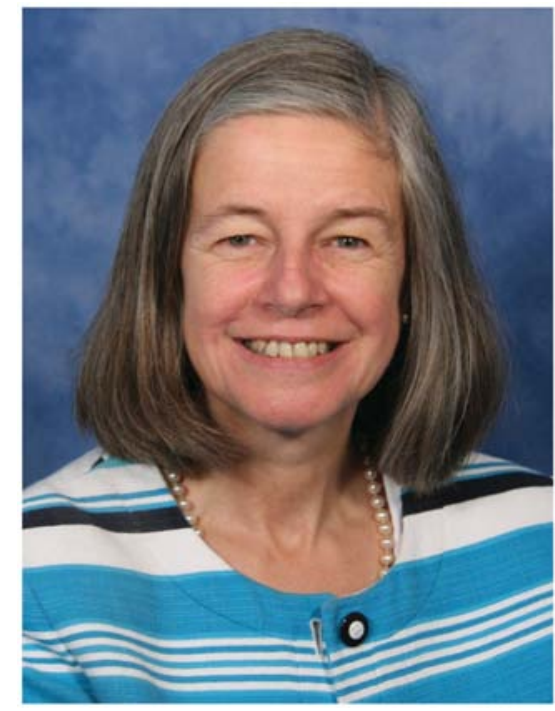

Figure 1. Professor Anne Greenough, Professor of Neonatology and Clinical Respiratory Physiology at King's College London (London, UK) and Chair of the 3rd Workshop on Paediatric Virology, October 7th, 2017, Athens, Greece.

Question: What new issues on Paediatric Virology do you think that our scientific community could be dealing with in the coming years?

Answer: Our ability to prevent and treat viral infections is rapidly increasing, for example with the development of many new potential respiratory syncytial virus (RSV) vaccines, antiviral agents and monoclonal antibodies. Given the morbidity related with other viral infections e.g., rhinovirus and metapneumovirus, related therapies to other viral agents will follow.

Question: Could Paediatric Virology be established as a separate paediatric subspecialty in the future? What are possible difficulties or limitations for such a proposal?

Answer: The number of Paediatric Virologists in any one country is likely to be small; hence, a separate paediatric subspecialty needs to be considered carefully, as some trainees may not be able to progress to consultant position.

Question: Almost 10 years ago, in the spring of 2007, at the Wirral University Teaching Hospital in Wirral, UK, the necessity of the valuable input of a specialised expert having clinical experience on Neonatology, as well as on recent advances on Molecular Virology was highlighted by all the members of the team. How many Paediatric Virologists are indeed needed in the UK?

Answer: I would suggest one in each UK deanery or reference centre providing they have the capacity to give comprehensive coverage for the UK between them. At the moment, in complicated cases, we contact our experts in viral diseases, who will be experts in adult and paediatric viral diseases.

Question: What are the current options for a paediatric trainee, who wants to be specialised in Paediatric Virology at the moment in the UK?

Answer: Masters of Sciences (MScs), Doctors of Philosophy (PhDs), Masters of Research (MRes), Diplomas, subspecialty of paediatric infectious diseases. 
Question: The PVSG has the great honor to offer to you on October 7th, 2017, the '2017 George N. Papanicolaou Humanitartian Award' for your outstanding academic, clinical, research and publishing contribution on the wealth, health and future of humanity. This award in 2015 was offered to Professor Demetrios Spandidos and in 2016 to the Nobelist Professor Harald zur Hausen, who will co-chair with you the 3rd Workshop on Paediatric Virology on October in Athens. Answer: I am very honoured and privileged to be awarded the '2017 George N. Papanicolaou Humanitarian Award' and take pleasure in accepting this award. Dr George N. Papanicolaou made an outstanding contribution to women's health by demonstrating that uterine cancer could be diagnosed by means of vaginal smear. His Pap smear is used worldwide for the detection and prevention of cervical cancer and other cytological diseases of the female reproductive system and has saved thousands of lives.

Question: Thank you for your answers and your support to our scientific attempt; we are looking forward to your co-chairship and your plenary lecture on October in Athens.

\section{References}

1. Greenough A, Theodoridou M, Kramvis A, Mammas IN, Christaki I, Koutsaftiki C, Koutsaki M, Kostagianni G, Portaliou D, Papadopoulou P, et al: Workshop on Paediatric Virology. Paediatric Virology Study Group, Athens, October 10, 2015.
2. Greenough A, Osborne J and Sutherland S (eds): Congenital, perinatal, and neonatal infections. Churchill Livingstone, Edinburgh, 1992.

3. Greenough A, Roberton NRC and Milner A (eds): Neonatal respiratory disorders. Taylor \& Francis, London, 1995.

4. Greenough A, Drysdale S, Broughton S and Bont L: The impact of viral infections on the long-term outcomes of prematurely born infants. Int J Mol Med 36: S89, 2015.

5. Mammas IN, Greenough A, Theodoridou M, Kramvis A, Christaki I, Koutsaftiki C, Koutsaki M, Portaliou DM, Kostagianni G, Panagopoulou P, et al: Current views and advances on Paediatric Virology: An update for paediatric trainees (Review). Exp Ther Med 11: 6-14, 2016.

6. Mammas IN, Greenough A, Theodoridou M and Spandidos DA: Paediatric Virology: A new paediatric subspecialty? A proposal at the Workshop on Paediatric Virology, Athens, October 10 2015. Exp Ther Med 11: 3-5, 2016.

7. Mammas IN, Theodoridou M, Kramvis A, Thiagarajan P Gardner S, Papaioannou G, Melidou A, Koutsaki M, Kostagianni G, Achtsidis V, et al: Paediatric Virology: A rapidly increasing educational challenge (Review). Exp Ther Med 13: 364-377, 2017.

8. Mammas IN and Spandidos DA: Athens-based meeting to discuss the paediatric virology crossroad in October 2017. Acta Paediatr 106: 1536, 2017. 